San Jose State University

SJSU ScholarWorks

$5-2018$

\title{
Obstetric Nurses' Perceived Barriers to Immediate Skin to Skin Contact after Cesarean Birth
}

Joelene Sarmiento Balatero

California State University, Northern California Consortium Doctor of Nursing Practice

Follow this and additional works at: https://scholarworks.sjsu.edu/etd_doctoral

Part of the Maternal, Child Health and Neonatal Nursing Commons

\section{Recommended Citation}

Balatero, Joelene Sarmiento, "Obstetric Nurses' Perceived Barriers to Immediate Skin to Skin Contact after Cesarean Birth" (2018). Doctoral Projects. 90.

DOI: https://doi.org/10.31979/etd.ca3v-qppr

https://scholarworks.sjsu.edu/etd_doctoral/90

This Doctoral Project is brought to you for free and open access by the Master's Theses and Graduate Research at SJSU ScholarWorks. It has been accepted for inclusion in Doctoral Projects by an authorized administrator of SJSU ScholarWorks. For more information, please contact scholarworks@sjsu.edu. 


\begin{abstract}
OBSTETRIC NURSES' PERCEIVED BARRIERS TO IMMEDIATE SKIN TO SKIN CONTACT AFTER CESAREAN BIRTH
\end{abstract}

Despite the strong evidence supporting immediate skin to skin contact (SSC) after birth, research suggests that patients who undergo cesarean births do not have the same opportunities for SSC as patients who undergo vaginal births. There are limited studies regarding provider attitudes surrounding the practice of immediate SSC after cesarean birth. The aim of this research was to understand obstetric nurses' perceived barriers to immediate SSC after cesarean section.

An exploratory qualitative design was used for the project. The semi-structured, open-ended interviews were conducted via video conferencing. Conventional content analysis methods were used to analyze the data, which yielded the primary overarching theme of "performing safe and effective skin to skin contact after cesarean birth". The participants identified both barriers and facilitators to SSC after cesarean. It was evident from the interviews that nurses strongly believe in the benefits of SSC after cesarean and try to implement it as often as possible, but various factors prevented SSC in the OR from occurring on a regular basis. This research can be used as a starting point for refining the practice of SSC after cesarean births.

Joelene Balatero

May 2018 
OBSTETRIC NURSES' PERCEIVED BARRIERS TO IMMEDIATE SKIN TO SKIN CONTACT AFTER CESAREAN BIRTH

\author{
by \\ Joelene Sarmiento Balatero
}

\author{
A project \\ submitted in partial \\ fulfillment of the requirements for the degree of \\ Doctor of Nursing Practice \\ California State University, Northern Consortium \\ Doctor of Nursing Practice \\ May 2018
}




\section{APPROVED \\ For the California State University, Northern Consortium Doctor of Nursing Practice:}

We, the undersigned, certify that the project of the following student meets the required standards of scholarship, format, and style of the university and the student's graduate degree program for the awarding of the Doctor of Nursing Practice degree.

Joelene Balatero MSN, RN, FNP-C, PHN,

Project Author

Cocusigned by:
Arlene Spllker 5/8/2018 Spilker (Chair)

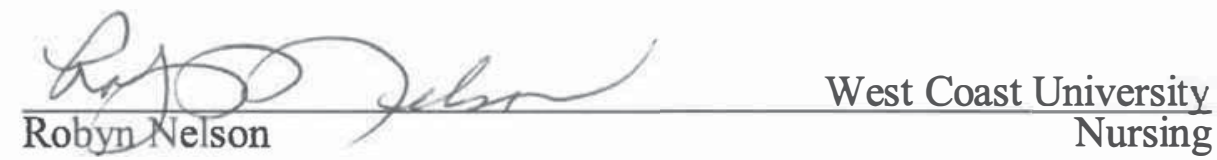

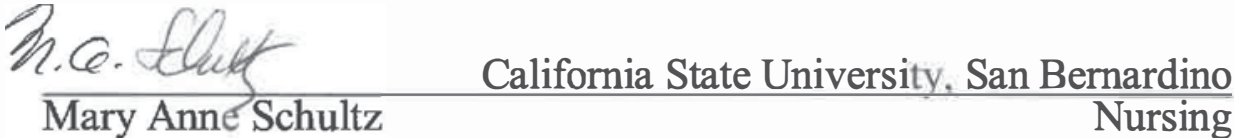




\section{AUTHORIZATION FOR REPRODUCTION}

\section{OF DOCTORAL PROJECT}

I grant permission for the reproduction of this project in part or in its entirety without further authorization from me, on the condition that the person or agency requesting reproduction absorbs the cost and provides proper acknowledgment of authorship.

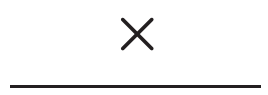

Permission to reproduce this project in part or in its entirety must be obtained from me.

Signature of project author:___oelene Balatero 


\section{ACKNOWLEDGMENTS}

To my chair, Dr. Arlene Spilker: Without your support, none of this would have been possible. Your guidance and encouragement were critical to my success. Thank you for everything you have done for me.

To my committee members, Dr. Robyn Nelson and Dr. Mary Anne Schultz: Thank you for your mentorship. I truly appreciated your feedback and support throughout this endeavor.

To Dr. Susan McNiesh and Dr. Lisa Walker-Vischer: Thank you for lending me your talent and expertise. You were a critical part of this journey, and you helped shape this project.

To my husband, Remar: When I decided I wanted to go back to school to pursue this personal goal of mine, we had a 3-year-old and twin 1-year-olds. Everyone else thought I was nuts, but not you. You supported me, and you never doubted my success. You held down our fort while I was pursuing my goals. I am so incredibly blessed to have you. I love you. Thank you for always encouraging me and supporting all (ok, most) of my ideas.

To my daughters, Dahlia, Rosalind and Juniper: I have many roles, but being your mother is my favorite. All three of you allowed me to experience birthing in its various forms, and your births inspired this project. I went back to school while you were all little hoping that you wouldn't notice that I was gone at school or busy with homework, but I know you knew. I am often short on sleep, time, and patience but you love me anyway and I thank you for that. I hope this serves as an example for you three to work hard and pursue your goals. Remember my girls that you can do anything you put your mind to. Mommy loves you all so very much. 
To my family, friends and colleagues: Thank you all for your pep talks, positivity and encouragement throughout this whole process.

To the nurses who volunteered their time for this project: Thank you for your time and contribution to nursing knowledge. Thank you for all you do. 
TABLE OF CONTENTS

Page

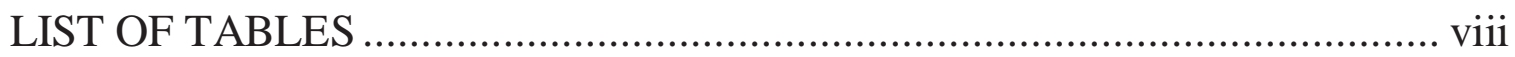

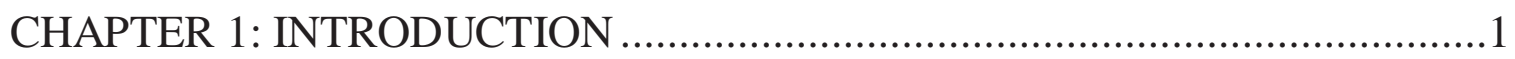

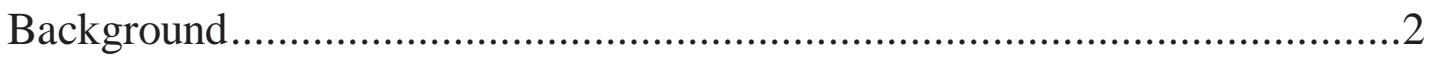

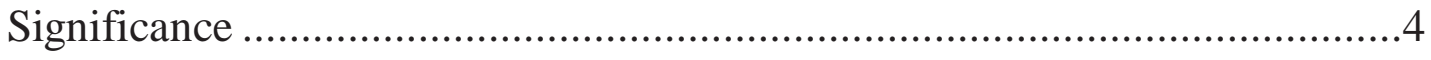

Problem Statement .....................................................................................

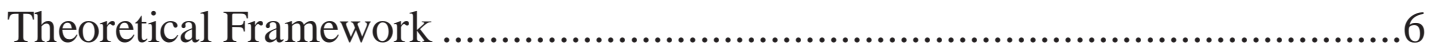

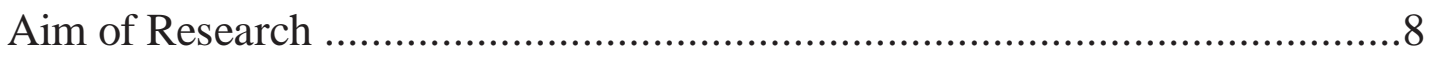

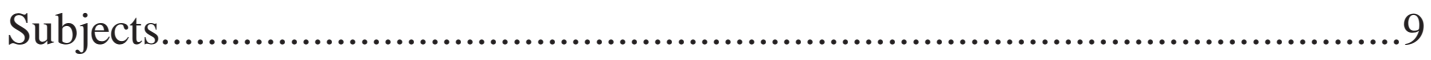

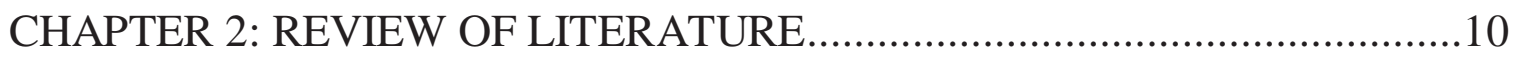

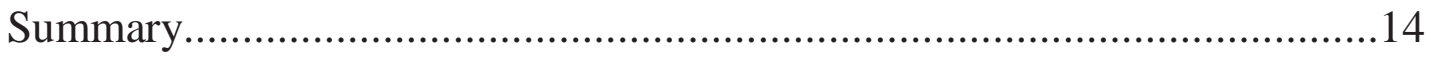

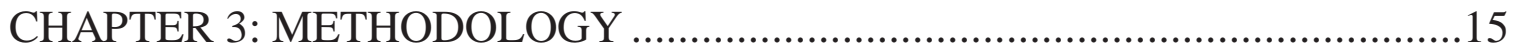

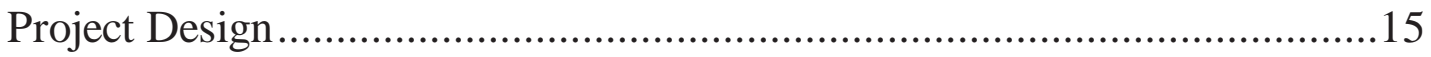

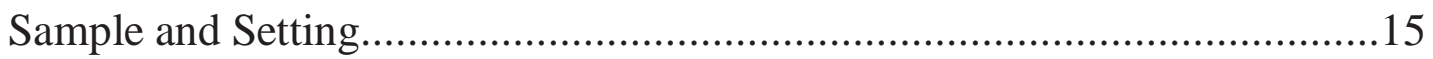

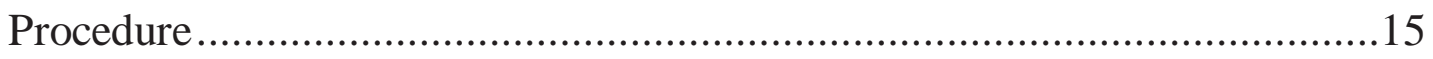

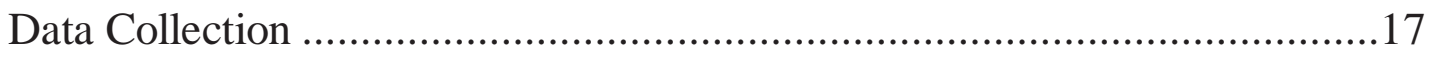

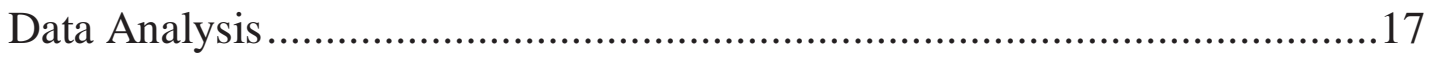

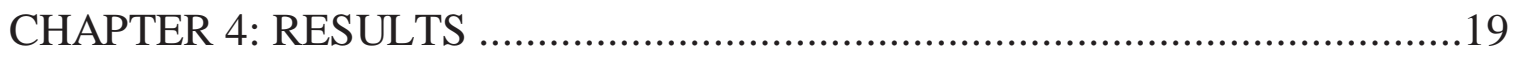

Participant Demographics .........................................................................19

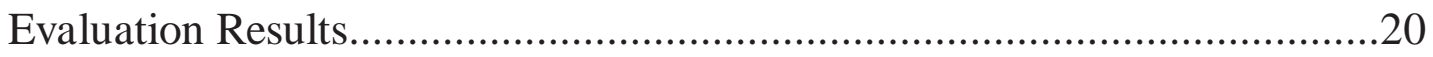

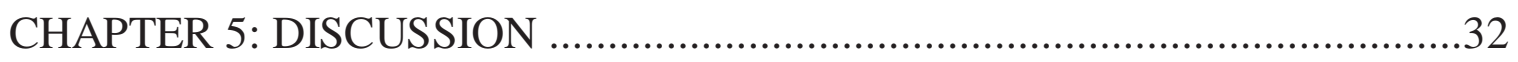

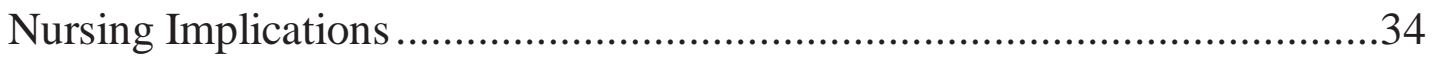

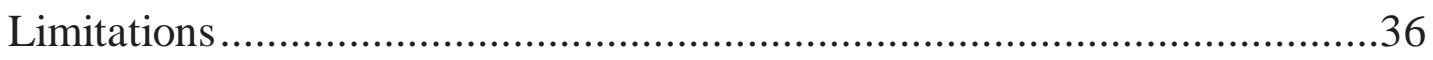


Conclusion

APPENDIX A: PATIENT DEMOGRAPHIC QUESTIONNAIRE ......................47

APPENDIX B: PARTICIPANT INTERVIEW QUESTIONS ...........................50

APPENDIX C: PROJECT PARTICIPANT CONSENT FORM ..........................52

APPENDIX D: INTERVIEW DATA THEMATIC UNITS................................55

APPENDIX E: PROCESS FOR THEMATIC ANALYSIS …….........................57

APPENDIX F: THEMATIC ORGANIZATION PROCESS ................................59 


\section{LIST OF TABLES}

Page

Table 1 Participant Demographic Data ...............................................................19 



\section{CHAPTER 1: INTRODUCTION}

Immediate skin to skin contact after vaginal birth has become the standard of care in most hospitals. The practice is recommended by multiple governing bodies in women's health (American Academy of Pediatrics [AAP], 2012; American College of Obstetricians and Gynecologists [ACOG], 2016; Association of Women's Health, Obstetric and Neonatal Nurses [AWHONN], 2013; World Health Organization [WHO], 2013). An established body of research and literature has long supported the benefits of immediate skin to skin contact (SSC) between mothers and neonates after birth (International Childbirth Education Association [ICEA], 2015).

Skin to skin contact is defined as the placement of the naked neonate directly onto the mother's bare chest, with no barriers in between the mother's skin and the baby's skin (ICEA, 2015). The vast benefits of SSC include improved thermoregulation, vital sign stabilization and regulation, normalization of neonate's blood glucose and the initiation and maintenance of a breastfeeding relationship (AAP, 2012; ICEA, 2015; WHO, 2013). Skin to skin contact has been shown to facilitate the breastfeeding relationship between mother and baby, and to increase the amount of time the baby is exclusively breastfed (ICEA, 2015). Increasing breastfeeding rates and the amount of time an infant is exclusively breastfed is a recommendation of the World Health Organization (2013), the Centers for Medicare \& Medicaid Services (2012), the American Academy of Pediatrics (2012): in addition, it is a perinatal core measure of The Joint Commission (2015). 


\section{Background}

The practice of SSC originated in Bogota, Colombia in 1979, as a potential solution for high infant morbidity and mortality rates in a maternal child unit with many high-risk infants. Additionally, shortages in staffing, equipment and other resources prompted Dr. Edgar Rey Sanabria, a professor of neonatology, to suggest that mothers have SSC, originally called "kangaroo mother care", with their infants (Greydanus \& Merrick, 2014). This desperate approach borne out of a dire clinical situation became an innovation in neonatal care.

In recent years, the terms "natural cesarean", "gentle cesarean", "womancentered cesarean" and "family-centered cesarean" have been used interchangeably to describe cesarean techniques and changes in the operating room environment to improve the surgical birth experience, which can often feel impersonal and detached for patients (Magee, Battle, Morton \& Nothnagle, 2014; Schmidt, 2015; Scutti, 2017). Depending on the facility, these changes may include the use of a clear surgical drape to allow for parents to watch their babies being born, playing music during the procedure, dimming the lights in the operating room and accommodating other reasonable parental requests to make the cesarean more personal and patient-centered (Brigham and Women's Hospital, 2013; Schmidt, 2015; Scutti, 2017). A central concept in the family-centered cesarean is allowing for SSC between mother and neonate to facilitate bonding immediately after birth (Magee et al., 2014). Interventions in the natural cesarean approach are adjusted to allow for immediate SSC; these include keeping the mother's arms free during the cesarean, placing the IV and blood pressure cuffs on the mother's non-dominant arm and moving EKG leads to make room for the baby on the maternal chest space (Brigham and Women's Hospital, 2013; Schmidt, 2015; Scutti, 2017). 
The first hour of life is a sensitive period and is often referred to in the literature as the "golden hour", "sacred hour" or "magic hour" (Crenshaw, 2014). Regardless of maternal birth experience (or type of delivery) and chosen feeding method (breast or bottle), immediate and uninterrupted SSC in the golden hour is an evidence-based practice recommendation (Baby Friendly USA [BFUSA], 2012). There is debate in the literature concerning what is considered immediate SSC, but the general consensus defines immediate SSC as being performed within 5 minutes of birth (Crenshaw, 2014). The golden hour is a limited time period wherein the mother and neonate form attachments to each other; therefore, it is recommended that SSC be initiated immediately and that all routine assessments and procedures be performed after the golden hour to allow for this critical bonding time between mother and neonate (Crenshaw, 2014).

Maternal-neonatal attachment and bonding are crucial to establishing and maintaining the breastfeeding relationship. Breastfeeding is the most ideal infant feeding method, and breastmilk is the recommended source of infant nutrition (BFUSA, 2012). The WHO and United Nations Children's Fund (UNICEF) established the Baby Friendly Hospital Initiative (BFHI) in 1991 to implement processes in hospitals that promote and support successful breastfeeding practices. Facilities may elect to achieve Baby-Friendly Designation through Baby-Friendly USA, Inc., which is the national accrediting body in the United States. Currently, there are more than 500 Baby-Friendly hospitals in the United States. This distinction means that the facility has met all of the criteria set forth by the BFHI and has met "the gold standard for mother/baby care practices for breastfeeding" (BFUSA, 2012, "For Parents", para. 1). One of the BFHI Guidelines and Evaluation Criteria for Facilities Seeking Baby-Friendly Designation (2016) states, "after cesarean birth, mothers and their infants should be placed in 
continuous, uninterrupted skin-to-skin contact as soon as the mother is responsive and alert, with the same staff support... regarding feeding cues, unless separation is medically indicated" (p. 14). Hence, SSC after cesarean is recommended and encouraged by BFUSA, and facilities seeking the Baby-Friendly designation should support this practice.

\section{Significance}

After cesarean delivery, it is feasible for skin to skin contact to be initiated in the operating room (Hung \& Berg, 2011). The standard and preferred method of anesthesia for cesarean sections is via a spinal or epidural approach, allowing for the woman to be awake and responsive during and after the surgery (Crenshaw, 2014). In general, current practice in the United States separates mothers and neonates for a period of one to four hours after a cesarean section (Francis, 2016). During the period immediately after cesarean birth, it is standard practice to perform routine care for the neonate, such as complete physical assessments, obtaining measurements, and administering medications, which contributes to further delay of immediate SSC (Crenshaw, 2014; Francis, 2016). The author's own anecdotal research has found that the clinical and sometimes acute nature of the cesarean delivery creates a perception that it is more of a surgery than a birth. In speaking with key stakeholders, such as cesarean mothers, obstetric nurses, and perinatal nurse educators, it is apparent that there is a disconnect in the cesarean experience, that could potentially be rectified by altering the interactions of the healthcare staff in the operating room during a surgical birth.

Research has shown that mothers are more satisfied with their surgical birth experience when they are able to have skin to skin contact with their 
newborns (Crenshaw et al., 2012; Phillips, 2013). Though the benefits of this practice are well-documented, women who undergo a cesarean delivery may not be given the same chances for immediate skin to skin contact with their newborns when compared to women who have vaginal births (Moran-Peters, Zauderer, Goldman, Baierlein \& Smith, 2014). In the United States today, one in three women will give birth via cesarean, making it the most common surgery in the country (Centers for Disease Control and Prevention [CDC], 2015). Current cesarean birth practices may hinder the provision of immediate SSC, resulting in a significant number of mothers and infants not receiving evidence-based care. Thus, there is a need for change involving skin to skin practices for women undergoing cesarean section.

The data regarding provider attitudes about practicing immediate SSC after cesarean are limited. In order for effective change to occur, there is a need for research regarding provider perceptions about barriers to immediate SSC after cesarean birth. Obstetric nurses have an active role in patient care during cesarean delivery, and their perspectives on the practice of SSC in the operating room can contribute to protocol and practice changes that potentially improve patient satisfaction and outcomes.

\section{Problem Statement}

Despite evidence showing that it is a safe and effective practice for many mothers, immediate SSC is seldom performed after cesarean delivery (MoranPeters, Zauderer, Goldman, Baierlein, \& Smith, 2014). There is limited research on the provision of immediate skin to skin contact after a surgical birth and the author did not locate any research regarding obstetric nurses perceptions of SSC 
after cesarean birth. The purpose of this project was to examine nurses' perceived barriers to practicing immediate skin to skin post Cesarean section.

\section{Theoretical Framework}

Nurses have the unique opportunity to influence the extraordinary moment when a woman becomes a mother. The maternal role attainment theory by Ramona Mercer focuses on a woman's transition into motherhood. The concept of immediate SSC after cesarean delivery promotes maternal-infant attachment and bonding, and facilitates maternal role attainment and becoming a mother. This middle-range nursing theory has its roots in several theoretical perspectives, and is influenced by Mercer's professional background. Mercer's extensive experience in pediatric and obstetric nursing fostered her interest in the process of becoming a mother and subsequently led to the development of her theory (Husmillo, 2013).

Mercer was taught and mentored by Reva Rubin, who was famous for her work in describing maternal role attainment and mother-infant attachment. Mercer's background in women's health, her interest in maternal role formation and mother-infant attachment processes assisted in the formation of her theory. Other theories that influenced Mercer's approach include Mead's role enactment theory, Turner's theory on the core self, Thornton and Nardi's role acquisition process, general systems theory, and several family theories. Due to the intricacy

of her research interests, it was necessary for Mercer to rely on several conceptual frameworks and approaches to expand and develop her theory (Meighan, 2010). Gathering perspectives from several conceptual backgrounds and theoretical frameworks helped shape and form the beginnings of the maternal role attainment/becoming a mother theory. 
Mercer (2004) further proposed a revision to her theory by retiring the term "maternal role attainment" and instead began using the term "becoming a mother". The term "maternal role attainment" seemed to suggest a static concept, whereas "becoming a mother" more aptly described the developmental and interactional process that is the transition into motherhood.

\section{Theoretical Assumptions}

The becoming a mother theory assumes that the mother is well-socialized and is relatively emotionally, physically, and mentally stable. The mother's unique personality must also be considered as her traits will influence her behavioral responses (Meighan, 2010). The infant is considered the mother's role partner and has a great impact on maternal role attainment and maternal identity. The intimate partner-mother relationship is crucial to maternal role attainment and its impact cannot be duplicated by any other person or relationship. Maternal identity and maternal attachment are dependent upon each other, and maternal attachment does not develop without maternal identity (Meighan, 2010).

Mercer (2004) describes becoming a mother as a dynamic phenomenon that involves four stages that ultimately lead to confidence in the maternal role. There are tremendous opportunities for the nurse to support a woman in each of these stages, from the time a woman prepares her body for pregnancy, to when she becomes pregnant, delivers her baby and is recovering from childbirth, to the exhilarating yet exhausting first few weeks of motherhood, and finally, when she is confident and strong in her maternal role and identity (Mercer, 2006). The anticipatory stage occurs in pregnancy, as the woman thinks of herself in the mothering role and psychologically prepares herself for motherhood. The formal stage is when she gives birth and looks to expert models to help her make 
decisions about how she wants to parent and care for her infant. The informal stage is when the mother transitions from rigidly following the expert models' advice to forming her own conclusions about mothering and parenting. The personal identity stage is when the mother finds congruence between herself and motherhood, thereby finding confidence and satisfaction in her maternal role (Mercer, 2004).

The becoming a mother theory has been extensively utilized in nursing research as well as in studies by other disciplines. The unique phenomenon that is motherhood and all the other concepts interwoven with it continue to mystify healthcare providers and nurses alike. Thus, Mercer's theory assists in providing a model which can guide healthcare providers to anticipate the mother's needs and facilitate her transition into motherhood.

\footnotetext{
Aim of Research

The aim of this project was to provide a basic understanding of barriers faced by obstetric nurses to the practice of SSC after cesarean. During a cesarean section, obstetric nurses play a large role in ensuring the well-being of the mother-infant dyad. They are crucial members of the healthcare team in a cesarean setting. Inclusion of the ideas and suggestions of key stakeholders is necessary for SSC to occur in the operating room. There were two research questions for this project. The first was: What are obstetric nurses' attitudes towards the provision of immediate SSC post cesarean? The second question was: What are the perceived barriers to immediate SSC after cesarean as reported by obstetric nurses?
} 


\section{Subjects}

The sample consisted of 10 obstetric nurses. Because subjects were sourced from personal and professional contacts, this sample was unique as it involved nurses from different hospitals. Inclusion criteria for the study were nurses with at least 5 years of experience,and currently practicing in the obstetric unit. Potential risks to the subjects included issues with confidentiality and psychological stress. The researcher took every necessary precaution to minimize these risks. Risk minimization strategies included obtaining informed consent and employing measures to maintain confidentiality, such as storage of data in a secure place, and ensuring participant anonymity. The participants were also instructed that they could withdraw from the project at their discretion anytime during the project. 


\section{CHAPTER 2: REVIEW OF LITERATURE}

There is limited literature regarding the provision of immediate SSC after a cesarean birth. A literature search was performed on the CINAHL and MEDLINE databases for studies done within the last 5 years using the keywords "skin to skin contact" and "cesarean". Between the two databases, these keywords produced roughly 75 results from peer-reviewed journals. This yielded research that was mostly focused on quality improvement projects to enhance the experience of women undergoing a cesarean birth by providing them with more opportunities for immediate skin to skin (Brady, Bulpitt \& Chiarelli, 2014; Grassley \& Jones, 2014; Hung \& Berg, 2011; Magee, Battle, Morton \& Nothnagle, 2014; Moran-Peters et al., 2014; Stone, Prater \& Spencer, 2014; Sundin \& Mazac, 2015). While the content of these quality improvement research projects was informative, the content did not discuss obstetric nurses' perspectives and perceptions on the practice of SSC after cesarean. Therefore, these studies were excluded in the literature review.

Another search was performed in the databases mentioned above using the same criteria but adding the keywords "obstetric nurses" and "perceived barriers". This search yielded only one study that explored nurse midwives' attitudes regarding SSC after cesarean, which is included in the literature review. There are presently no studies that have focused on obstetric nurses' perceived barriers to this practice.

Although scarce, the literature on perspectives surrounding immediate SSC after cesarean birth is emerging. The available literature can be categorized into three groups: research on provider perspectives, or patient perspectives, and research including perspectives of both provider and patient. 


\section{Provider Perspectives}

Zwedberg, Blomquist and Sigerstad (2015) sought to examine the barriers faced by midwives when trying to implement SSC after cesarean birth. Qualitative analysis methods were used to interpret the responses. The theme that emerged from this research was "fighting an uphill battle", since the midwives felt that there was a constant struggle with patients and other providers to increase skin to skin contact after cesarean delivery. Implications for nursing practice included recommendations for more patient and staff education (Zwedberg, Blomquist, \& Sigerstad, 2015). This is the only study found that discusses providers' perceived barriers and provided qualitative insight on midwives' experiences with skin to skin after cesarean.

Koompan, Callaghan-Koru, Alaofin, Argani, and Farzin (2016) explored clinician views that contribute to uninterrupted skin to skin contact after both cesarean and vaginal births of healthy, full term infants. A qualitative research design using semi-structured interviews was utilized in the study, which was performed at a university-affiliated community hospital in the United States. The sample consisted of five nurses from the obstetrics unit, five nurses from the neonatal intensive care unit (NICU), one obstetrician and one neonatologist. The research concluded that several factors influence the practice of skin to skin after delivery including inadequate staffing and lack of clinician education. Parental motivation and education were identified as facilitators to SSC (Koopman et al., 2016). The barriers to immediate SSC included the lack of a clinical policy or procedure to guide SSC after delivery, and a lack of maternal-infant eligibility criteria (Koopman et al., 2016). The strength of this study is that it provided feedback from members of the interdisciplinary team, not just nurses. 


\section{Patient Perspectives}

To explore the maternal experience surrounding skin to skin immediately after Cesarean, Frederick et al. (2016) interviewed and observed eleven women ages 23-38 years on their perspectives of holding the baby soon after surgical birth. The research was conducted in a Texas medical center and the data was quantified using qualitative analysis methods. The primary theme which emerged from the data was mutual caregiving, involving the mother-neonate connection, reciprocal relationship, and the benefits of skin to skin contact. There were two secondary themes which emerged: a) maternal awareness of the cesarean procedure and environment and b) paternal involvement in the skin to skin process. Implications for practice included the increased opportunity for nurses to facilitate skin to skin contact after cesarean and the opportunity for advanced practice registered nurses to change policies to support skin to skin contact after surgical birth (Frederick, Busen, Engebretson, Hurst, \& Schneider, 2015). The strength of this qualitative study is the detailed accounts of mothers' perception of the skin to skin experience after cesarean delivery. The authors also included data on how long it took to transfer the baby to the mother's bare chest which was a unique addition to the body of knowledge.

\section{Provider and Patient Perspectives}

In a study involving two university hospitals, Niela-Vilen et al. (2013) had three objectives. The first was to compare and describe the early physical contact of mothers and their preterm or sick neonates. The second was to explore the staff's perceived barriers and facilitators to early physical contact. The third was to describe the association between early physical contact and breastfeeding. The study design was a structured survey conducted over a five month period in two university hospitals in Finland. The participants included all preterm or sick 
infants who needed neonatal intensive care and their mothers who filled out the survey. The study concluded that the implementation of early physical contact varied greatly between the two university hospitals (Niela-Vilen et al., 2013). The most common obstacle to early physical contact was infants' unstable condition and cesarean section. There was a moderate correlation between early physical contact and initiation of breastfeeding. Implications for future research include reevaluating barriers to early physical contact, and establishing guidelines to facilitate early physical contact between mothers and their preterm or sick neonates (Niela-Vilen et al., 2013). The strength of this research is the large sample size ( $\mathrm{n}=381)$. A limitation of this study is the lack of further exploration of the barriers to skin to skin contact surrounding a cesarean delivery of preterm or sick babies.

Redshaw, Hennegan and Kruske (2014) aimed to describe the timing, duration, and type of early physical contact between mother-infant dyads, and their relationships to breastfeeding duration and maternal health after delivery. The association between the type of birth and the nature of the first contact was also examined. A retrospective analysis of women who gave birth in a four month period in Queensland, Australia was performed. The analysis excluded stillbirths, neonatal deaths, infants who needed neonatal intensive care admission, and mothers who needed critical care interventions during delivery. After exclusion criteria was determined, a total of 4574 women were included in the study and given the questionnaire packages, which they could return via mail, complete online, or over the phone with a trained female interviewer. Data were analyzed using both multivariate and univariate statistical methods, and results indicated that women who had an unmedicated vaginal birth held their babies sooner, and for longer periods of time than women who had augmented vaginal births and/or 
cesarean sections. Those who underwent unmedicated vaginal births were also more satisfied with their early physical contact. Early physical contact was moderately correlated with maternal health in the vaginal birth group, but not in the cesarean birth group (Redshaw, Hennegan, \& Kruske, 2014). One limitation of this study was a lack of detailed exploration on the factors that caused differences and gaps in the early physical contact experience. Also, cultural differences in the practice of early physical contact were not explored.

\section{Summary}

The benefits of immediate skin to skin are evident in the literature, and this practice is considered evidence-based care. However, immediate skin to skin contact is not routinely practiced in patients who have a surgical birth, and there is limited research that explains this phenomenon. This literature review suggests that there is insufficient research surrounding registered nurses' perspectives on the practice of immediate skin to skin contact after cesarean birth. Nurses are key stakeholders in facilitating skin to skin contact between mothers and neonates immediately after birth, yet very little research has been conducted that explores their perceptions. Of note, the input of nurses was only examined in one of the articles discussed above and only ten nurses were interviewed for that study. Anecdotally, recent conversations with some perinatal educators revealed that although some hospitals may have protocols on skin to skin in the operating room, they are not being followed by most nurses, which provides further impetus for the examination of nurses' attitudes. 


\section{CHAPTER 3: METHODOLOGY}

\section{Project Design}

This project was an exploratory qualitative study which sought to understand obstetric nurses' perceived barriers to SSC after cesarean delivery. Participants were interviewed regarding their experiences.

\section{Sample and Setting}

Participants were recruited by word of mouth and through personal and professional contacts. Purposive sampling methods gathered the sample size of 10 labor and delivery nurses. Inclusion criteria for the study were nurses with at least 5 years of experience at the bedside and nurses who were currently practicing in the obstetric unit. Interviews with participants were done via online video conferencing, which gave participants the convenience of answering the interview questions in a setting of their own choosing. Informed consent was obtained from participants prior to beginning the data collection process (see Appendix C). Participants were given an electronic \$25 Amazon gift card at the end of their interview.

\section{Procedure}

This project received IRB approval on November 13, 2017. The participant recruitment began immediately after IRB approval. Data was collected from December 12, 2017 to February 10, 2018. The interviews were recorded using the recording feature of an online video conferencing program known as Zoom. The recordings were then sent to a transcriber service for transcription. 


\section{Potential Benefits}

There were no direct benefits to the study participants. Some indirect benefits included contributing to the production of research that will further provide insight regarding the practice of SSC after cesarean birth. This insight could potentially bridge gaps in care and aid in changing hospital SSC protocols and procedures to accommodate patients undergoing cesarean birth.

\section{Potential Risks}

Although minimal, there were some anticipated potential risks to subjects. The subjects were interviewed regarding their experiences with SSC after cesarean. Some subjects may have felt uncomfortable answering some of the interview questions and this could have led to psychological discomfort. Also, as with any research study, there could be potential problems with loss of confidentiality. Every attempt was made to prevent any psychological distress and/or breaches in confidentiality.

\section{Risk Minimization}

To minimize the risk of psychological distress, the subjects were informed that their participation was voluntary, and that they could skip questions they did not wish to answer. Because the interview was qualitative, they were also able to include only the information that they offered voluntarily. Participants would have been referred to a mental health professional if psychological stress occurred during the project.

Confidentiality was discussed with participants in the informed consent document as well as at the start of the interview process. All necessary precautions were taken to minimize risk and ensure participant confidentiality, including coding of participant information and data extracted. The researcher and members 
of the investigation team had sole access to the data. The data was kept in a locked file cabinet in the researcher's home office and will be destroyed before the IRB approval expiration date of November 13, 2018.

\section{Data Collection}

After the consent forms were signed and returned to the researcher, interviews were scheduled. At the start of the interview, the researcher reviewed the informed consent process and confidentiality once more, and then proceeded with open-ended, semi-structured interviews that were 10 to 30 minutes in duration. Six open-ended questions were used in participant interviews (see Appendix B). Participants were also asked to complete a demographic questionnaire about their personal information (age, gender, ethnicity) and their nursing experience (employment status, educational background, years of experience) (See Appendix A). To ensure data trustworthiness, an investigation team was utilized to analyze the data. The investigation team consisted of the researcher, a DNP program faculty, the researcher's project chair and the researcher's program advisor. The investigation team researchers have all completed human subjects training, along with one being a qualitative research expert and one with significant experience in qualitative research.

\section{Data Analysis}

Conventional content analysis techniques as described by Hsieh and Shannon (2005) were used to analyze the data. According to Hsieh and Shannon (2005), "qualitative content analysis is defined as a research method for the subjective interpretation of the content of text data through the systematic classification process of coding and identifying themes or patterns" (p. 1278). In this process, immersion in data is necessary. First, all of the transcriptions were 
read. After reading through all of the transcriptions once, the researchers then read each transcript thoroughly, highlighted words or phrases that described the participant's response, and wrote in the margins, words or phrases that captured the participant's emotion. After repeating this process with three to four transcripts, preliminary codes were assigned, and these codes were used to analyze the remaining transcriptions (See Appendix E, F). The themes which emerged were used to describe the participants' perceptions and experience. The investigation team repeated the conventional content analysis process with the transcribed data. Upon completion of this process, the investigation team met to compare results. 


\section{CHAPTER 4: RESULTS}

\section{Participant Demographics}

Demographic data of participants were collected upon completion of the interviews (Table 1). All of the participants $(n=10)$ were female and currently employed in a hospital as a labor and delivery $(L \& D)$ nurse. The majority of the participants (90\%) were white. The age range, education level, and years of nursing experience of the participants varied.

Table 1 Participant Demographic Data

\section{Characteristic}

Gender

Age

Ethnicity

\section{Summary}

Male

Female

$18-25$

26-34

35-44

45-54

55-64

$65+$

White

Black

Asian

Hispanic

Other

Yes

No

$0-4$

5-10

11-15
Value

$0 \%$

$100 \%$

$0 \%$

$40 \%$

$20 \%$

$20 \%$

$20 \%$

$0 \%$

Length of time as an L\&D nurse (years)

$0 \%$

$0 \%$

Currently employed as a hospital L\&D nurse

$100 \%$

$0 \%$ 
Education level

Associate's degree $\quad 0 \%$

\section{Evaluation Results}

Conventional content analysis yielded the primary overarching theme of "performing safe and effective skin to skin contact after cesarean birth". Six thematic categories were identified within the primary theme: safety, staffing, professional obstacles, drivers for change, logistical challenges, and regional and facility variances (Appendix D). Several subcategories were also identified and grouped under the appropriate thematic category.

\section{Safety}

The participants identified several factors related to safety that affected their ability to facilitate skin to skin contact. As one nurse said:

Ninety-five percent of the time, our moms are fine...they could probably

hold their babies, but then I think everybody is just cautious and apprehensive because they worry about safety.

Some factors identified included keeping the sterile field and maintenance of infection control measures in the operating room (OR), and concern about the OR temperature being too cold for SSC.

There was also awareness among all the nurses that generally cesarean section mothers and babies are high-risk and/or are at higher risk for complications. Frequent side effects of anesthesia medications used in cesarean 
deliveries and labor is nausea and shivering-like tremors. One participant mentioned:

We reassure anesthesia that if mom is going to get nauseous or whatnot that we are going to be there to pick up the baby right away...we understand baby's safety comes first and yes, we will take the baby off the chest if something were to happen

Most of the participants stated that an obstructed line of sight and being further away from the mother-infant dyad during their role as a circulating nurse necessitated that another nurse be staffed solely to facilitate SSC in the OR and monitor the mother-infant dyad. Specifically, there should be a nurse assigned to the baby whose only responsibility is to monitor the baby during SSC. This nurse would maintain a line of sight to the baby at all times while SSC is happening. As one nurse stated:

If I was the only nurse in the room, that would definitely be a barrier. I don't think you could do skin-to-skin with the mom, but in our hospital, we do because we have a nurse for the baby and a nurse for the mom.

Three participants noted that in their facilities, SSC was performed in the OR after almost all cesarean deliveries, and the reason this was possible was because they are fully staffed with another nurse assigned in the operating room whose sole responsibility is to facilitate SSC for mother and baby. One of these respondents noted that she would "absolutely not" be comfortable doing SSC without the assigned baby nurse there, as she did not feel this would be a safe practice. 


\section{Staffing}

Staffing during a cesarean section is crucial to facilitating SSC, according to the participants. Concepts such as cost-effectiveness versus having enough staff to support SSC in the operating room were identified by the participants as barriers. One participant stated:

The charge nurse is looking at staffing as quick turnover--I want to get that second nurse in and out as quickly as possible. Unfortunately, the way things work at our facility is that a gentle $C$-section would require that second nurse to be at the maternal bedside longer than they would like to ensure adequate productivity on the unit. How one defines productivity has been a varying notion throughout the years. It's relative in terms of what we see as learning to support skin-to-skin meaning what's best for mom and baby as opposed to what's best for manpower on the unit...I think unfortunately what usually happens is staffing and the availability of resources trumps what is best for mom and baby.

Another participant said, "Depending on staffing, sometimes the NICU nurse will stick around for a while and support skin-to-skin, but it's -it's kind of a moving target as far as who has the resources available on each day and each shift". Many of the participants mentioned inadequate staffing as a major deterrent to SSC in the OR.

One of the nurses, whose facility does SSC in the OR on a regular basis, stated that her unit is well-staffed, noting:

They always try to send in someone to assist the circulator, and I would say they do that ninety-five percent of the time. It might not be the entire time, but during the beginning of the case at least through to the last count, usually there's another nurse there, which helps a lot. 


\section{Professional Obstacles}

All the participants stated that they were unaware of any formal standardized policy and/or procedure in their current place of employment that supported SSC after cesarean. A lack of education among patients, nurses, and other healthcare providers was also identified as an obstacle to implementing SSC after cesarean. One respondent stated:

Other health care workers have to realize that this is beneficial for the patient, too. So we need education all the way down the line, and sometimes it is starting with the management, and you have to just continue to show them and demonstrate to them that this is important.

Another respondent added that a lack of training and education for all the nursing and medical staff on how to successfully implement SSC after cesarean is a barrier.

Almost all of the participants stated that buy-in from administration and other members of the healthcare team is crucial to facilitating SSC in the operating room. As one participant mentioned, "Doctor buy-in is a big one. So the surgeon, just ensuring them that we're not gonna break the sterile field...the second one is anesthesia. It's getting those buy-ins from the surgeon and also from the anesthesiologist". One nurse mentioned that at her hospital, part of the time-out procedure prior to all cesareans is to ask if the whole healthcare team and the mother would like to do SSC in the OR. She mentioned that although this was part of their normal time-out process, they actually never do SSC in the OR due to lack of staff buy-in. This is a strange yet important finding, which supports the need for consensus among the staff to support SSC.

Competing interests among the staff and issues with the current recovery workflow, was a factor that was identified by some of the participants. In this case, 
workflow can be described as the systems and processes used by the unit for cesarean recovery. A respondent stated: “I just feel like they're trying to get everything done in the OR instead of trying to facilitate skin-to-skin”. Another participant mentioned that the NICU nurses take charge of the baby after delivery, and their priority is to do assessments and measurements. Also, she shared that the current workflow they have in place does not support uninterrupted SSC. She stated:

Initially the baby will be skin-to-skin for a couple of minutes and then moved to the warmer usually after five or ten minutes so they can do assessment and meds, height weight, all that stuff, and then back to skin-toskin to do breastfeeding...it's just kind of a different flow. And the removal of the baby is not my favorite practice, but unless we change our whole flow of recovery, it's hard,I think to wait an hour to do things.., it just doesn't work in the workflow.

Inconsistency in teamwork, or collaboration among the personnel, was another identified professional obstacle hindering consistent SSC after cesarean. A participant stated that practicing SSC in the OR was wholly dependent on which nurses, obstetricians and anesthesiologists were working on the case, as some staff were more supportive of SSC than others. Another shared a recent experience where she had trying to facilitate SSC for a patient who was vomiting after her cesarean section as she was being transported out of the OR. She stated:

The anesthesia provider had the audacity to tell me, 'she can't hold the baby right now'. And I'm, like, I'm right here ready to take this baby. She seems okay right now. Let her hold her baby. I mean the patient hadn't held her baby the entire case and to get pushback even afterwards about it--it's bad. 
Another respondent shared that teamwork is crucial to the practice of SSC in the OR, stating:

You work as a team with the NRP (Neonatal Resuscitation Preparation) nurse, who is usually a NICU nurse in the OR and they quickly dry the baby off and give it a quick assessment...but between the two of us, we get baby right onto mom's chest... NRP is there and they really try to help facilitate because they are definitely into mom/baby bonding.

These responses illustrate the value of collaboration, and how it can either facilitate or obstruct SSC in the OR.

Some of the participants discussed that SSC is the norm in their unit, and that they are expected to provide SSC if possible, provided that the mom and baby are both stable. One respondent stated:

I certainly remember holding my kids skin-to-skin; you know, they popped the baby up on your chest after it was born--wiped it off and stuck them up there. And they're in their 20s and 30s. So this is not a new thing, but I know there's an emphasis on it now. So you know, unless there's some reason not to, I just feel like that's a natural part of care...in all situations where it's possible, we do it. It's the expectation.

\section{Logistical Challenges}

Participants were asked to discuss the major differences between vaginal and cesarean births. In general, their answers were related to spatial and logistical difficulties, which they identified as potential barriers to SSC after cesarean. The participants stated that during a cesarean, there are usually more people and equipment in the room than during a vaginal birth. Many identified the concept of awkward maternal space as a barrier, citing there was not enough space on the 
mother's body, between her chest and open abdomen separated by the sterile drape, to do SSC. Sterile drapes are placed prior to the cesarean section to separate sterile space from non-sterile space. The drape is placed at the top of the mother's abdomen to differentiate between the sterile and non-sterile space.

Maternal positioning was also a barrier as some participants identified that during a cesarean, mom is usually flat on her back, unable to move, with her arms extended and strapped down onto arm boards. This positioning made some nurses wary of placing a "slippery" baby on the maternal chest space. One nurse also mentioned:

I've had two moms now in the OR have issues with breathing because of the relatively big baby on their chest because you don't have much space between the drape and the mom to kind of place the baby there...you've got tubes and wires and all that kind of stuff in the OR that you have to navigate.

Another factor discussed by some participants was the concept of anesthesia "ownership" of the head of the OR table, or the space where SSC will be occurring. A nurse stated, "The anesthesiologist--because they are at the head of the bed caring for the patient--they're the primary driver of what care happens in the OR". Another respondent mentioned:

We have been working towards making skin-to-skin offered in the C-section rooms. So we tend to do it if mom is stable enough and if the anesthesiologist - it's in a lot of communication with our anesthesiologist it seems like because they're the ones, I think, who are the most concerned with skin-to-skin happening, not so much the rest of the team in the room. One participant also mentioned: "Anesthesia probably has the biggest pushback because the OR is their area. And I get it. We do things very 
differently in $L \& D$ than the rest of the OR world that makes anesthesia very uncomfortable”. Other items, such as IV and EKG placement, were also factors to consider when planning SSC in the OR. Regarding the cesarean mother, a respondent noted, "she has all these, a blood pressure cuff and a pulse ox, and IVs, and all this stuff attached to her arm. I've had anesthesiologists or CRNAs who are really supportive, and they assist with that as well".

\section{Regional and Facility Variances}

Many of the respondents mentioned geographical and facility-dependent variances on the practice of SSC after cesarean. Some nurses noted that they do SSC after all vaginal births and in the OR for some cesarean deliveries in one facility, but in another facility, the practice was to do SSC after cesarean in the recovery room. One participant, with experience at multiple facilities as a traveling nurse, noted that certain geographical locations are more educated and open to family-centered care and more "natural" approaches to birth, stating "in the past three years between Northern and Southern California, Northern California is more open to different birth plans, and they're more centered around the family". Another participant stated:

Before I left Minnesota, it had switched from if patients asked for it, we would do it to 'this is what we do; is that okay with you?' And now [in my current facility] skin-to-skin is the expectation and the norm.

The concept of the uninterrupted golden hour was also identified by some respondents as a facility-based variance, with some facilities completely supporting no interruptions in the first hour of life, and others that do not. One participant stated: 
For vaginal births, we do skin-to-skin right away. As long as the baby comes out crying nice and vigorous, nice and pink they'll do skin-to-skin for about an hour, and then after that is when we'll do the assessment. So we do pretty much everything on mom, vital signs every 30 minutes and they changed even the vitamin K shot on skin-to-skin as well--it's supposed to help soothe the babies, which I've noticed a difference. We try to initiate breastfeeding within the first hour based on infant cues...but for C-sections we don't do it right after...the baby's born, we bring the baby over to the warmer, put their bands on, wrap them up, and then we bring them wrapped up to mom, and then once they're in the recovery room is when we do skin-to-skin...I've read that some hospitals do skin-to-skin in the OR, but at ours, I don't know the reason why they don't, but we don't. In comparing vaginal versus cesarean births, all of the participants mentioned notable differences in the practice of SSC, with the general consensus that SSC during a vaginal birth is "easier" and more widely accepted by nurses and other members of the healthcare team.

\section{Drivers for Change}

Participants discussed driving forces and attempting to facilitate practice change in several of their responses. Patient satisfaction scores, positive reviews of the hospital within the community, and meeting the expectations of the patients and their families were identified by participants as potential drivers for change. One respondent shared:

Sometimes it just comes down to Press-Ganey scores. You might have to go from one hospital site to another, read their Press-Ganey scores, see what 
they are doing. Sometimes that drives change because, as we know, hospitals live on patient satisfaction scores.

In discussing patients' expectations, one respondent stated:

I always ask patients, I say 'this is how we do it: skin-to-skin, delayed cord clamping, skin-to-skin for at least he first hour. Are you okay with that?' And, you know, 99\% of people say, yeah, that's what I want. Another respondent stated, "I think the biggest barriers are the providers saying 'We can't do it' because when I've asked moms, more moms than not want to do it in the OR if you offer it to them". Many of the participants echoed this response, stating that many of the patients and their families want and expect SSC. Many of the participants also mentioned baby-friendly designation as a driver for practice change. Some of the participants were currently working in a baby-friendly hospital, and others were working towards achieving baby-friendly designation. The participants who were currently working in a baby-friendly facility performed SSC after cesarean on a regular basis in order to comply with the goals of their unit and keep their designation. Additionally, those who were working on obtaining the designation knew that their current SSC practices need improvement in order to comply with the BFUSA initiatives.

Furthermore, all the nurses supported and were knowledgeable about the benefits of SSC, which was another facilitator. All of the participants reported positive experiences with SSC in their professional practice, noting that SSC often helps the cesarean mother. A respondent shared:

I've had all positive experiences, really no negatives about SSC. Even with moms who had a traumatic birth last time and weren't able to have their babies right away, they just seem to actually flower and just really bond 
well with their babies. Their negatives are gone quickly once they get to hold that baby.

Another nurse added:

The cesarean is traumatic on your body. And when moms get their babies and hold them skin-to-skin, you see it where, their shakes and shivers from the epidural just go away and it relaxes the mom. It elicits this response in mothers. It's amazing how it just helps them.

Some of the nurses recalled their own personal experiences of SSC, with one nurse stating:

You know--even with my personal experience, my first baby was extremely premature, so he was immediately taken to the NICU, and I don't think it affected my bonding with my baby because I love my son-he's eight now and he's my baby, but it just took something away, versus when I had my daughter who was full-term, skin-to-skin, nobody took her from me for more than an hour and it just gave me time to focus on everything that's just happened.

Concepts of perseverance and advocacy were also discussed by the participants. One nurse felt strongly about being a patient advocate, stating, " $I$ think it - to me, first and foremost, it's a patient advocacy issue, and if this is what is right for the patient and what the patient wants, then we need to be advocating for that”. Another nurse noted the importance of persistence, stating that, “sometimes people don't pay attention to the latest research supporting SSC, but you just have to, if you feel strong enough, you just have to keep persevering”. The general consensus among the respondents is that they do everything in their power to facilitate SSC and even if it does not happen in the operating room, they were determined to have the mother-infant dyad do SSC in the recovery room. Also, 
they often involved the birth partners by giving them the opportunity to do SSC if the mother was unable to do so. Some participants mentioned that the supportive culture in their unit, which viewed SSC after cesarean as the expectation rather than the exception, helped to facilitate the practice. 


\section{CHAPTER 5: DISCUSSION}

This goal of this project was to learn more about the perspectives of obstetric nurses about SSC and what, in their professional opinion, are barriers to this practice in the cesarean birth setting. The literature is limited on obstetric nurses' viewpoints about SSC after cesarean and the findings of this project supported that overall, obstetric nurses want to provide SSC after cesarean in a safe and effective manner. Challenges with safety, staffing and logistics were discussed by the participants as well as professional barriers, and varying practices between geographical location and facilities. The respondents also discussed concepts that were facilitators for changing their current practices to support SSC after cesarean.

There were many interesting findings from this project, but the most significant and serious discovery was the lack of formal policies and procedures supporting SSC after cesarean at any of the participant facilities. This was best illustrated, perhaps, by the experience of one respondent, whose facility includes SSC in the OR as part of the time out procedure prior to each cesarean, yet has never actually done SSC in the OR. The findings indicate that the practice of providing immediate SSC is not considered a priority during the cesarean. The providers are busy completing numerous tasks, including the nurse whose responsibilities include charting, instrument counts and other tasks that seem to take precedence over facilitating SSC for the mother-infant dyad. Even the nurses who are regularly doing SSC in the OR reported that there are no formal policies that support this practice, although it is the expectation in their unit. Expectation to perform evidence-based care without a formal policy could lead to inconsistencies in care and increased liability. This highlights a disconnect that would likely 
improve with a standardized policy and procedure which supports immediate SSC in the OR and allocates for resources, such as appropriate staffing, that allow for this practice.

Moreover, all the participants knew about SSC being evidence-based care and the numerous benefits associated with the practice, yet only four had ever done SSC in the OR setting. This finding suggests that the ability of the nurse to practice evidence-based care is governed by the practice norms and rules set forth by the unit and the facility. The participants who were routinely practicing SSC in the OR reported that this was the norm and it was the expectation of their facility and unit.

A new study done in Australia by Stevens, Schmeid, Burns and Dahlen (2018) explored SSC in cesarean delivery using video ethnographic research. This research discussed in detail the concepts of ownership surrounding the maternalinfant dyad during a cesarean, with anesthesia "owning" the top half of the maternal body, the obstetrician "owning" the bottom half, and the nurse midwife "owning" the baby. This "ownership" of the maternal body contributed further to the maternal feelings of disconnect and loss of control in a cesarean birth. Parallel to the findings of Stevens et al. (2018), many of the respondents for this research mentioned the same concept of ownership, stating the head of the bed is "owned" by anesthesia, and their consent (or lack thereof) to do SSC in the OR was the most important factor in whether the nurses could successfully implement SSC in the OR. Also parallel with this project's findings, Stevens et al. (2018) identified several factors that acted as barriers to SSC in the OR including, but not limited to: efficiency versus doing what is best for the mother-infant dyad, a large workload with decreased time to complete several tasks, and logistical challenges in the OR (Stevens et al., 2018). 
The results of this project were congruent with the findings of Zwedberg, Blomquist, and Sigerstad (2015), who explored midwives' perspectives on providing SSC after cesarean. Some of their results included a lack of education among providers and patients as well as issues with teamwork, collaboration and workload as barriers to the practice of SSC after cesarean. These barriers, they concluded, contributed to SSC not being performed. This project similarly found that SSC in the OR was hindered by challenges with team buy-in, a heavy amount of nursing duties, understaffing and deficits in staff education and knowledge about the importance of SSC.

Redshaw, Hennegan and Kruske (2014) reported that women who had vaginal births held their babies sooner and for longer periods of time than women who had cesareans. Parallel to their results, the majority of the nurses in this project reported that they had never done SSC in the OR, but were knowledgeable and very comfortable facilitating SSC after a vaginal birth. This finding further supports the discrepancies in SSC provided during vaginal births versus cesareans.

\section{Nursing Implications}

This project had the goal of establishing foundational data to determine baseline knowledge about the barriers to the practice of skin to skin contact after cesarean births. The data gathered from this project will be used to modify protocols and guide performance improvement projects to support immediate skin to skin contact, leading to more positive patient outcomes and increased patient satisfaction with the cesarean section experience.

It was evident from this project that there is a great need for formal policies and protocols that standardize the practice of SSC in the OR. Clearly, the literature supports SSC due to its many benefits for mother and neonate and it is 
considered evidence-based practice. Nursing practice is backed by evidence, standardized procedures, and hospital policies and protocols. It is difficult for nurses to practice evidence-based care by facilitating SSC after cesarean without formal policies and procedures to support and guide them.

Baseline assessments should be conducted to help identify gaps in knowledge, education, and resources. These factors should be examined to determine their impact on immediate and uninterrupted skin-to-skin practices after cesarean. Along with formalized policies and procedures, rectifying these gaps would potentially have an effect on overall consensus and buy-in of the healthcare team.

It is costly to conduct needs assessments and to train staff on new processes and policies. It will also be costly to overhaul the current practices of a unit to support immediate SSC in the OR as this could mean hiring and staffing more nurses in the unit to assist in facilitating SSC. It will be difficult in a busy unit to give the cesarean mother an uninterrupted golden hour. However, it is key for administrators and staff alike to understand the importance of this practice as it relates to patient satisfaction, positive patient outcomes, and meeting perinatal core measures. The overarching goal of changing current practice is to provide an improved cesarean experience for patients by normalizing as much of the cesarean birth process as possible. Thus, revenue could possibly be increased for hospitals that offer and advertise the option for skin to skin after cesarean, which may justify the investment cost for hospital administration.

Implications for nursing education include teaching and promoting this practice as safe and effective as evidenced by the literature. This information and evidence will be disseminated to the nurses, obstetricians, anesthesiologists and others who care for patients undergoing cesarean deliveries. It would also help to 
include in the education the potential barriers to the practice and the solutions to those barriers. The entire healthcare staff should have adequate training, preferably in a simulated environment, to aid them in identifying how to best implement this in their units with their teams. Prior to implementing any action items, it is crucial to first have a thoroughly researched and achievable policy and procedure in place.

Future research should focus on effective policies and procedures which support SSC in the OR. It would also be useful to elicit the feedback of obstetricians, anesthesiologists and administrators on the practice of SSC in the OR. Understanding the patient experience of mothers who have SSC in the OR would provide a unique perspective to the healthcare professionals constructing new policies and procedures. Overall, the input of patients, providers and administrators would be influential in developing and implementing effective processes. Lastly, research should be conducted to document the effects, if any, of uninterrupted skin to skin after cesarean on the breastfeeding relationship as there are many measures on breastfeeding that are set forth by the governing bodies in healthcare.

\section{Limitations}

There were some limitations to this project. The first was related to the sample selection process. Specifically, a sampling bias existed when using a purposive method in that the overall representativeness of the sample was skewed. Also, because this author contacted personal and professional networks to find other potential study participants, it is likely that the participants may have had something in common with the author, which again represents a sampling bias. Another limitation was the small sample size of nurses. Although smaller sample sizes are ideal in qualitative methods, it is still important to recognize the 
size of a sample as a limitation. It is also important to discuss that the results from this study cannot be generalized.

\section{Conclusion}

The project was an exploratory qualitative study that focused on nurses' experiences and perceived barriers to the practice of skin to skin contact after a surgical birth. Implications for nursing administration and education were also examined, along with suggestions for future research. The benefits of immediate skin to skin are well-researched, and this practice is considered evidence-based care. However, immediate skin to skin contact is not routinely practiced with patients who have a cesarean birth, and there is limited research surrounding why this is the case. An initial review of the literature highlighted some of the gaps in the current research, and the results of this study may aid in closing some of those gaps.

Nurses have the privilege of witnessing and influencing the pivotal moment when a woman becomes a mother. In a cesarean delivery, obstetric nurses, along with the interdisciplinary healthcare team, are responsible for the care and safety of mother-infant dyads. They are the patient advocates, and they have the power to act as change agents to increase skin to skin contact in the operating room after a surgical delivery. Thus, it is critical to consider their perspectives on potential barriers to this practice in order to facilitate effective operational change. This project will hopefully contribute to practice and protocol changes that will aid in making skin to skin after cesarean delivery a standard practice. The findings of this project will be used as a springboard for future research and for developing policies and procedures which support evidence-based nursing care of cesarean patients. 



\section{REFERENCES}

American Academy of Pediatrics. (2012). Policy Statement: Breastfeeding and the Use of Human Milk. Retrieved from http://pediatrics.aappublications.org/content/pediatrics/129/3/e827.full.pdf

American College of Obstetricians and Gynecologists. (2016). Frequently Asked Questions: Breastfeeding Your Baby. Retrieved from https://www.acog.org//media/For-Patients/faq029.pdf

Association of Women's Health, Obstetric and Neonatal Nurses. (2013). Women's health and perinatal nursing care quality draft measures specifications. Retrieved from https://c.ymcdn.com/sites/www.awhonn.org/resource/resmgr/Downloadables /perinatalqualitymeasures.pdf

Baby Friendly USA. (2012). FAQs For parents. Retrieved March 23, 2018, from https://www.babyfriendlyusa.org/faqs/for-parents

Baby Friendly USA. (2012). Our philosophy. Retrieved March 23, 2018, from https://www.babyfriendlyusa.org/about-us/our-philosophy

Baby Friendly USA. (2016). . In The Baby-Friendly Hospital Initiative: guidelines and evaluation criteria for facilities seeking Baby-Friendly designation. Retrieved from file://C:/Users/joele/Downloads/GEC2016\%20(1).pdf

Bailey, J. (2015, August 31). Skin-to-skin care for term and preterm infants in the neonatal ICU. Pediatrics, 136, 596-599. http://dx.doi.org/10.1542/peds.20152335 
Bigelow, A., Power, M., MacLellan-Peters, J., Alex, M., \& MacDonald, C. (2012, April 26). Effect of mother/infant skin-to-skin contact on postpartum depressive symptoms and maternal physiological stress. Journal of Obstetric, Gynecologic \& Neonatal Nursing, 41, 369-382. http://dx.doi.org/10.1111/j.1552-6909.2012.01350.x

Brady, K., Bulpitt, D., \& Chiarelli, C. (2014). An interprofessional quality improvement project to implement maternal/infant skin to skin contact during cesarean delivery. Journal of Obstetric, Gynecologic \& Neonatal Nursing, 43, 488-496. http://dx.doi.org/10.1111/1552-6909.12469

Brigham and Women's Hospital. (2013). The gentle cesarean: a new option for moms-to-be. Retrieved from http:/healthhub.brighamandwomens.org/thegentle-cesarean-a-new-option-for-moms-to-be\#sthash.lkf4zpq5.dpbs

Centers for Disease Control and Prevention. (2015). Birth in the United States, 2014 (NCHS Data Brief No. 216). Retrieved from https://www.cdc.gov/nchs/data/databriefs/db216.pdf

Centers for Disease Control and Prevention. (2016). Pregnancy mortality surveillance system. Retrieved September 14, 2016, from http://www.cdc.gov/reproductivehealth/maternalinfanthealth/pmss.html

Centers for Medicare \& Medicaid Services. (2012). Medicaid coverage of lactation services. Retrieved from https://www.medicaid.gov/MedicaidCHIP-Program-Information/By-Topics/Quality-ofCare/Downloads/Lactation_Services_IssueBrief_01102012.pdf 
Crenshaw, J. T. (2014). Healthy birth practice \#6: keep mother and baby together- it's best for mother, baby, and breastfeeding. The Journal of Perinatal Education, 23, 211-217. http://dx.doi.org/10.1891/10581243.23.4.211

Francis, S. (2016). Skin to skin after cesarean [Video file]. Retrieved from https://www.acog.org/About-ACOG/ACOG-Departments/Patient-Safetyand-Quality-Improvement/How-I-Practice/Skin-to-Skin-After-Cesarean

Frederick, A. C., Busen, N. H., Engebretson, J. C., Hurst, N. M., \& Schneider, K. M. (2015). Exploring the skin to skin contact experience during cesarean section. Journal of the American Association of Nurse Practitioners, 28, 3138. http://dx.doi.org/10.1002/2327-6924.12229

Grassley, J. S., \& Jones, J. (2014). Implementing skin-to-skin contact in the operating room following Cesarean birth. Worldviews on Evidence-Based Nursing, 11, 414-416. http://dx.doi.org/doi 10.1111/wvn.12057

Greydanus, D. E., \& Merrick, J. (2014, July 24). Newborn care: what we can learn from the kangaroo mother. Frontiers in Public Health, 2, 96. http://dx.doi.org/10.3389/fpubh.2014.00096

Hsieh, H., \& Shannon, S. E. (2005). Three approaches to qualitative content analysis. Qualitative Health Research, 9, 1277-1288. http://dx.doi.org/10.1177/1049732305276687

Hung, K. J., \& Berg, O. (2011). Early skin to skin after cesarean to improve breastfeeding. The American Journal of Maternal Child Nursing, 36, 318324. http://dx.doi.org/doi: 10.1097/NMC.0b013e3182266314 
Husmillo, M. (2013). Maternal role attainment theory. International Journal of Childbirth Education, 28, 46-48. Retrieved from http://search.ebscohost.com.hmlproxy.lib.csufresno.edu/login.aspx?direct=tr ue \&db=rzh\&AN=104292456\&site=ehost-live

International Childbirth Education Association. (2015). Position Paper Skin to Skin Contact. Retrieved from http://icea.org/wpcontent/uploads/2016/01/Skin_to_Skin_Contact_PP.pdf

Koopman, I., Callaghan-Koru, J. A., Alaofin, O., Argani, C. H., \& Farzin, A. (2016). Early skin-to-skin contact for healthy full-term infants after vaginal and caesarean delivery: a qualitative study on clinician perspective. Journal of Clinical Nursing, 25, 1367-1376. http://dx.doi.org/10.1111/jocn.13227 1367

Magee, S. R., Battle, C., Morton, J., \& Nothnagle, M. (2014). Promotion of a family-centered birth with gentle cesarean delivery. Journal of the American Board of Family Medicine, 27, 690-693.

http://dx.doi.org/10.3122/jabfm.2014.05.140014

Meighan, M. (Ed.). (2010). Ramona T. Mercer: Maternal role attainmentbecoming a mother. Nursing theorists and their work (7th ed., pp. 581-598). Maryland Heights, MO: Mosby Elsevier.

Mercer, R. T. (2004). Becoming a mother versus maternal role attainment. Journal of Nursing Scholarship, 36, 226-232. http://dx.doi.org/10.1111/j.15475069.2004.04042.x 
Mercer, R. T. (2006). Nursing support of the process of becoming a mother. Journal of Obstetric, Gynecologic, \& Neonatal Nursing, 35, 649-651. http://dx.doi.org/10.1111/j.1552-6909.2006.00086.x

Mercer, R. T., \& Walker, L. O. (2006). A review of nursing interventions to foster becoming a mother. Journal of Obstetric, Gynecologic, \& Neonatal Nursing, 35, 568-582. http://dx.doi.org/10.1111/j.1552-6909.2006.00080.x

Moran-Peters, J. A., Zauderer, C. R., Goldman, S., Baierlein, J., \& Smith, A. E. (2014). A Quality Improvement Project Focused on Women's Perceptions of Skin-to-Skin Contact After Cesarean Birth. Nursing for Women's Health, 18, 294-303. http://dx.doi.org/10.1111/1751-486X.12135

Niela-Vilen, H., Axelin, A., Salantera, S., Lehtonen, L., Tammela, O., Salmelin, R., \& Latva, R. (2013). Early physical contact between a mother and her NICU-infant in two university hospitals in Finland. Midwifery, 29, 13211330. http://dx.doi.org/ http://dx.doi.org/10.1016/j.midw.2012.12.018

Phillips, R. (2013). The sacred hour: Uninterrupted skin to skin contact immediately after birth. Newborn \& Infant Nursing Reviews, 13, 67-72. Retrieved from http://www.medscape.com/viewarticle/806325_10

Redshaw, M., Hennegan, J., \& Kruske, S. (2014). Holding the baby: Early mother-infant contact after childbirth and outcome. Midwifery, 30, e177e187. http://dx.doi.org/http://dx.doi.org/10.1016/j.midw.2014.02.003 
Schmidt, J. (2015). The gentle cesarean: more like a birth than an operation. Retrieved from https://www.npr.org/sections/healthshots/2015/03/09/390977656/the-gentle-cesarean-more-like-a-birth-than-anoperation

Scutti, S. (2017). 'Gentle' c-sections are growing in popularity. Retrieved from https://www.cnn.com/2017/06/13/health/gentle-natural-c-section/index.html

Stevens, J., Schmeid, V., Burns, E., \& Dahlen, H. G. (2018, February 26). Who owns the baby? A video ethnography of skin-to-skin contact after a caesarean section. Women and Birth Journal of The Australian College of Midwives. http://dx.doi.org/https://doi.org/10.1016/j.wombi.2018.02.005

Stone, S., Prater, L., \& Spencer, R. (2014). Facilitating skin-to-skin contact in the operating room after Cesarean birth. Nursing for Women's Health, 18, 486499. http://dx.doi.org/10.1111/1751-486X.12161

Sundin, C. S., \& Mazac, L. B. (2015). Implementing skin-to-skin care in the operating room after Cesarean birth. American Journal of Maternal Child Nursing, 249-255. http://dx.doi.org/doi: 10.1097/NMC.0000000000000142.

The Joint Commission. (2015). Facts about patient-centered communications. Retrieved September 21, 2016, from https://www.jointcommission.org/facts_about_patientcentered_communications/

The Joint Commission. (2016). Specifications Manual for Joint Commission National Quality Measures. Retrieved September 4, 2016, from https://manual.jointcommission.org/releases/TJC2016A/MIF0170.html 
World Health Organization. (2013). Recommendations on newborn health. Retrieved from http://www.who.int/maternal_child_adolescent/documents/guidelinesrecommendations-newborn-health.pdf

World Health Organization. (2016). MDG 5: improve maternal health. Retrieved September 14, 2016, from http://www.who.int/topics/millennium_development_goals/maternal_health/e $\mathrm{n} /$

Zwedberg, S., Blomquist, J., \& Sigerstad, E. (2015). Midwives' experiences with mother-infant skin-to-skin contact after a caesarean section: 'fighting an uphill battle'. Midwifery, 215-220. http://dx.doi.org/doi: 10.1016/j.midw.2014.08.014. 
APPENDICES 
APPENDIX A: PATIENT DEMOGRAPHIC QUESTIONNAIRE 
Participant Demographic Questionnaire

\section{Personal Information}

1. Please indicate your gender:

a) Male

b) Female

2. Please indicate your age:

a) $18-25$

b) $26-34$

c) $35-44$

d) $45-54$

e) $55-64$

f) 65 and above

3. Please indicate your ethnicity:
a) White
b) Black
c) Asian
d) Hispanic
e) Other

If other, please specify:

\section{Nursing Experience}

1. What is your current employment status:

a) Employed at a hospital

b) Not currently employed at a hospital

2. Are you currently a nurse practicing in a labor and delivery unit?

a) Yes

b) No

3. What is your highest level of education completed:

a) Associate's Degree (ADN)

b) Bachelor's Degree (BSN)

c) Master's Degree (MSN)

d) Doctorate Degree (DNP or PhD)

e) Post-doctorate degree 
4. How long have you been a nurse?
a. 0-4 years
b. 5-10 years
c. 11-15 years
d. 16-20 years
e. 21-25 years
f. 26-30 years
g. 31-34 years
h. 35 years and above

5. How long have you been an obstetric nurse?
a) 0-4 years
b) 5-10 years
c) $11-15$ years
d) 16-20 years
e) 21-25 years
f) 26-30 years
g) 31-34 years
h) 35 years and above 
APPENDIX B: PARTICIPANT INTERVIEW QUESTIONS 
Participant Interview Questions

1. Tell me about your experience of providing skin to skin contact after birth?

2. How do you feel about facilitating skin to skin care after birth?

3. In your opinion, what are the major differences in facilitating skin to skin care after vaginal birth versus after cesarean birth?

4. What are your experiences in facilitating skin to skin care after cesarean birth?

5. What assistance or support is needed to facilitate skin to skin care after cesarean birth?

6. What are the barriers to facilitating skin to skin care after cesarean birth? 
APPENDIX C: PROJECT PARTICIPANT CONSENT FORM 


\section{PROJECT PARTICIPANT CONSENT FORM}

\section{Dear Participant:}

My name is Joelene Balatero and I am a student in the California State University Northern California Consortium Doctor of Nursing Practice program. The Northern California Consortium is a joint program between San Jose State University and Fresno State University. I am working on a project titled Obstetric Nurses' Perceived Barriers to Skin to Skin Care After Cesarean Birth. My project chair is Dr. Arlene Spilker, Assistant Professor in The Valley Foundation School of Nursing at San Jose State University.

The Project: This project seeks to identify obstetric nurses' opinions and perceived barriers to providing skin to skin care after cesarean birth. In this project, no patients will be interviewed and no patient information will be accessed. The participants will be obstetric nurses who provide care to cesarean birth patients.

These participants will be asked to answer a brief questionnaire regarding their personal demographics and nursing experience. The participants will also be asked to participate in individual interviews which will last approximately 30 minutes to 1 hour. The interviews will occur via video conferencing and will be recorded for transcription purposes only. The interviews will ask participants about their opinions on skin to skin care as well as their experience with skin to skin care in both vaginal births and cesarean births.

Participants will receive a \$25 Amazon gift card upon completion of their interview.

Risks/Benefits: There are no anticipated risks for participating in this study. Your participation requires completion of a brief demographics questionnaire. Your participation will also require participating in a 30 minute to 1 hour interview about your opinions on and experience with skin to skin care during deliveries. Participants may feel sensitive in disclosing information they perceive as negative, however, all information collected will be confidential and will not be disclosed to anyone outside of the research team.

The participant interviews will occur via video conferencing, and a time most convenient for the participants will be arranged. Participants will complete the interview following their consent to participate and will have the option to refuse to be recorded. Participants will have the option to review only their individual recording and notes if requested. Data collected from the interviews will help determine the barriers to skin to skin care after cesarean as perceived by obstetric nurses.

It is unlikely that participants will be exposed to undue stress or discomfort as a result of their involvement in this project. 
Confidentiality: Results of this project may be published but no names or identifying personal information will be included for publication. Project records will be kept confidential to the extent allowed by law. Participants will have the option to review their individual recording and notes if requested. Data will be kept in a locked file cabinet in the researcher's home with only the researcher having access to collected data. Following data compilation, analysis and interpretation, all data collected during the process of the project will be destroyed after three years. Notes and recordings will be destroyed immediately following transcription.

Right to Refuse: Your participation is voluntary and you are free to withdraw from participation at any time without suffering penalty or loss of benefits or services you may otherwise be entitled to. You have the right to participate in the interview without it being recorded, if you so wish.

Contact Information: If you have additional questions or would like to know the results of the project, please contact Joelene Balatero via phone at (714) 351-3611 or email at joelene.balatero@gmail.com. You may also contact the Institutional Review Board at California State University, Fresno at (559) 278-4468.

Conflict of Interest: The researcher, Joelene Balatero, declares no conflicts of interest relating to the results of this study.

Consent Clause: I have carefully read and/or I have had the terms used in this consent form and their significance explained to me. By signing below, I agree that I am at least 18 years of age and agree to participate in this evaluation project. I will indicate by initialing either yes or no below whether I consent to have my interview recorded. If you do not wish to participate, the consent form should be left blank.

How to submit consent: The consent form can be returned back to the researcher via fax at (714) 782-6060 or via email as a PDF or JPEG document to joelene.balatero@gmail.com .

I consent to have my interview recorded.

Yes No

Participant's Printed Name: Signature:

Witness Printed Name: Signature: 
APPENDIX D: INTERVIEW DATA THEMATIC UNITS 
Subcategories, categories and overarching theme from the interview data

\begin{tabular}{lll}
\hline Subcategory & Category & Overarching Theme \\
\hline $\begin{array}{l}\text { Proximity to baby and keeping line of sight for } \\
\text { observation, cold OR temperature, risk for } \\
\text { neonatal complications, maternal health } \\
\text { problems/maternal health stability, infection } \\
\text { control measures }\end{array}$ & Safety & $\begin{array}{l}\text { Providing safe and } \\
\text { effective skin to skin } \\
\text { contact after } \\
\text { cesarean birth }\end{array}$ \\
$\begin{array}{l}\text { Efficiency versus evidence-based practice, heavy } \\
\text { workload, need another nurse }\end{array}$ & Staffing & \\
$\begin{array}{l}\text { Lack of formal policies and procedures, lack of } \\
\text { education for staff and families, lack of buy-in } \\
\text { from administration down, teamwork issues, } \\
\text { competing priorities, buy-in from nurses in } \\
\text { different roles; anesthesia "ownership" }\end{array}$ & $\begin{array}{l}\text { Professional } \\
\text { obstacles }\end{array}$ \\
$\begin{array}{l}\text { Awkward maternal space and positioning, not } \\
\text { enough space on maternal body to accommodate }\end{array}$ & $\begin{array}{l}\text { Logistical } \\
\text { challenges }\end{array}$ \\
$\begin{array}{l}\text { Championing change in practice, perseverance, } \\
\text { advocacy, culture and expectation of unit and } \\
\text { facility, nursing knowledge of benefits of SSC, } \\
\text { increased patient satisfaction scores, meeting } \\
\text { patient desires and expectations }\end{array}$ & $\begin{array}{l}\text { Drivers for } \\
\text { change }\end{array}$ \\
\hline
\end{tabular}


APPENDIX E: PROCESS FOR THEMATIC ANALYSIS 


\section{Process for thematic analysis}

\begin{tabular}{|c|c|c|}
\hline Step & $\begin{array}{l}\text { Analysis } \\
\text { Process }\end{array}$ & Participant quote \\
\hline 1 & Meaning Unit & $\begin{array}{l}\text { "We need to have anesthesia who's with it because, you know, } \\
\text { sometimes they're just, like, no, no, no, no, this baby is in the } \\
\text { way... I do believe that we have anesthesia providers who are } \\
\text { more, like, willing to accommodate skin-to-skin... So, I think, you } \\
\text { know, you need - everybody in the team needs to be open to it." }\end{array}$ \\
\hline 2 & Condensation & $\begin{array}{l}\text { It is necessary for anesthesia and everyone on the team to be open } \\
\text { to doing skin-to-skin contact. }\end{array}$ \\
\hline 3 & Code & Staff consensus about skin-to-skin contact \\
\hline 4 & Subcategory & Lack of buy-in among staff \\
\hline 5 & Category & Professional obstacles \\
\hline
\end{tabular}


APPENDIX F: THEMATIC ORGANIZATION PROCESS 
Process for organizing condensed meaning units into subcategories and categories

\begin{tabular}{|c|c|c|}
\hline Condensed Meaning Unit Interpreted & Subcategory & Category \\
\hline $\begin{array}{l}\text { SSC is not possible because the nurse is unable to } \\
\text { see baby and feels it is unsafe }\end{array}$ & $\begin{array}{l}\text { Proximity to baby and keeping } \\
\text { line of sight for observation }\end{array}$ & \multirow{3}{*}{ Safety } \\
\hline $\begin{array}{l}\text { The OR temperature is cold so nurse is worried } \\
\text { about doing SSC safely }\end{array}$ & Cold OR temperature & \\
\hline $\begin{array}{l}\text { Nurse needs to make sure that sterile field is } \\
\text { maintained }\end{array}$ & Infection control measures & \\
\hline $\begin{array}{l}\text { Nurse feels like what is best for the unit } \\
\text { supersedes what is best for the patient }\end{array}$ & $\begin{array}{l}\text { Efficiency versus evidence-based } \\
\text { care }\end{array}$ & \multirow{3}{*}{ Staffing } \\
\hline $\begin{array}{l}\text { Nurse has many tasks to complete as the primary } \\
\text { circulator }\end{array}$ & Heavy workload & \\
\hline $\begin{array}{l}\text { Nurse needs another RN in the room to facilitate } \\
\text { SSC }\end{array}$ & Need another nurse & \\
\hline $\begin{array}{l}\text { There are no formal policies and procedures that } \\
\text { support and direct staff to practice SSC in the OR }\end{array}$ & $\begin{array}{l}\text { Lack of formal policies and } \\
\text { procedures }\end{array}$ & \multirow{3}{*}{$\begin{array}{l}\text { Professional } \\
\text { Obstacles }\end{array}$} \\
\hline $\begin{array}{l}\text { Need more education on how to safely do SSC in } \\
\text { the OR as well as the benefits of SSC in the OR }\end{array}$ & Lack of education among staff & \\
\hline $\begin{array}{l}\text { Anesthesia owns the head of the OR table and } \\
\text { nurses need their approval to do SSC in the OR }\end{array}$ & Anesthesia ownership & \\
\hline $\begin{array}{l}\text { Mom is flat on the table and the positioning is very } \\
\text { awkward and makes it hard to do SSC. }\end{array}$ & Awkward maternal positioning & \multirow{3}{*}{$\begin{array}{l}\text { Logistical } \\
\text { challenges }\end{array}$} \\
\hline $\begin{array}{l}\text { There is a lot of equipment in the room and on } \\
\text { maternal body }\end{array}$ & Equipment in the way & \\
\hline There is no space on maternal body to do SSC & No space on maternal body & \\
\hline $\begin{array}{l}\text { Keep educating others about benefits of SSC even } \\
\text { if they don't support it, just keep going }\end{array}$ & Perseverance & \multirow{3}{*}{$\begin{array}{l}\text { Drivers for } \\
\text { change }\end{array}$} \\
\hline Patients want to have SSC and love having it & $\begin{array}{l}\text { Meeting patient desires and } \\
\text { expectations }\end{array}$ & \\
\hline Nurse advocates for patient's wish to have SSC & Advocacy & \\
\hline
\end{tabular}



